\title{
Effectiveness of Health Education Session on Knowledge of High School Students Regarding Plastic Use and Its Health Hazards
}

\author{
Rida Abid $^{1 *} \quad$ Muhammad Hussain $^{2} \quad$ Iram Majeed $^{3} \quad$ Muhammad Afzal $^{4} \quad$ Kausar Parveen ${ }^{4}$ \\ Syed Amir Gilani ${ }^{5}$
}

1. BS Nursing, Lahore School of Nursing, The University of Lahore, PO box 54000, Lahore, Pakistan

2. Assistant Professor, Lahore School of Nursing, the University of Lahore, PO box 54000, Lahore, Pakistan

3. Nursing Instructor, Lahore School of Nursing, the University of Lahore, PO box 54000, Lahore, Pakistan

4. Associate Professor, Lahore School of Nursing, the University of Lahore, PO box 54000, Lahore, Pakistan 5. Professor, FAHS the University of Lahore, PO box 54000, Lahore, Pakistan.

\begin{abstract}
Introduction: Plastic is widely used due to its low cost and different functional properties but it has many severe adverse effects on consumer's health in many direct and indirect ways. Plastic waste pollutes the environment and it is a threat to human life. So, there is a great need to reduce plastic use and plastic waste hazards. Methods: A quasi- experimental, quantitative, before and after study design was conducted among the students total $(\mathrm{n}=60)$ in the high school of Ali Raza Abad Raiwind Road Lahore, Pakistan from September 2018 to December 2018. The educational intervention involve three education session about plastic use and its health hazards in which the researcher educate the students about health hazards of plastics, prevention of plastic objects as well as health complications. Results: A total of 60 children participated in the study, the majority of the participants were boys. The mean before the educational intervention is 8.98 (Standard deviation 3.281) and after the educational intervention is 16.85 (Standard deviation 3.036). The mean difference between the two mean is 7.867. There is a statistically significant difference before and after the educational intervention. The educational intervention is highly effective because the significant value is 0.00 Conclusions: The result of the study shows that students have adequate knowledge about health hazards of plastic use. The ill effects of plastic can be reduce by educational intervention among students.
\end{abstract}

Keywords-Plastic use. Health education. Health hazards

DOI: $10.7176 / \mathrm{JHMN} / 72-09$

Publication date:March $31^{\text {st }} 2020$

\section{I.INTRODUCTION}

An environmental hazard is a substance, state, or event which is capable of producing possible threats to the surrounding or adverse effects on human health (Shiv, K. \& R. Dagar, 2018). Plastic is widely used due to its low cost and different functional properties but it has many severe adverse effects on consumer's health in many direct and indirect ways (Kumar. P, 2018). Plastic is made of plasticizers which is used to promote plasticity and flexibility in plastic materials. The most common plasticizers are pthalates (DEHP (Di-Ethylhexyl Phthalate), and DINP (Di-Isononyl Phthalate). DEHP has many uses such as footwear, printing inks, toys, food wraps etc. They have potential to cause endocrine disruptions, reproductive effects and impaired development. Major components of plastic such as (polyvinyl chloride, dioxins and plasticizers) causes major health problems e.g. hormonal imbalance, reproductive impairment, breast and testicular cancer. Plastic harms are evident in pregnant women as well as in newborns by direct contact with the plastic objects. (Babayemi, J. O., et al., 2016). In plastic consumption, to give flexibility and shape, phtahlates are used. They are used in a variety of prducts such as toys, food containers and plastic wraps.

It has also a potential to cause hormonal disruption like BPA (Bisphenol A), asthma in children and lower IQ for a developing fetus (Rodgers, K. M., et al., 2014). Unintended poisoning such as chemical poisoning (exposure to acids, detergents, plastic waste, and poisonous gases) kills 350, 000 people globally each year (Shiv, K. \& R. Dagar, 2018). During pregnancy, the plastic chemicals such as Biphenol A may exhibit adverse developmental effects on feotus such as reduced survival, low birth weight, delayed growth of offspring and of puberty (Dobrzyńska, M., et.al., 2018). The plastic bag use is very common among community so there is a great need for awareness regarding plastic hazards. To reduce the plastic use consumption, it is necessary to educate the public through different educational strategies. To reduce the risk of being exposed to chemicals like BPA (Bispehnol A), never heat or microwave your food in a plastic container, as it's believed that heating up the plastic can increase the amount of chemicals and toxins that leak into your food (Zen, I.S., et al., 2014). The increase consumption of plastic materials and its negative impacts on health put urgency to this problem (Kumar. P, 2018). Since in 1800s, the industrial revolution has been risen and it leads to increase the plastic pollution. To provide preferred environment many actions should be taken by health professionals including interactive and effective lectures in the educational systems and encouraging its stability throughout education life is important (Hammami, M. B. A., et al., 2017). Burning of plastic made things (tubs, dishes, pipes, polythene bags etc.) causes toxic smoke with 
dangerous chemicals. By burning of plastic dioxin and styrene gas produces which can lead to hormone disruption and cancer of different organs in a human being. Styrene gas specifically damages the nervous system. These chemicals are dangerous for not only us, but also for burners and neighbors. (Ni, H. G., et.al., 2016). Plastic waste pollutes the environment and it is a threat to human life. So, there is a great need to reduce plastic use and plastic waste hazards. For this purpose education is extremely important factor as education has potential to change people's knowledge, attitude and behavior toward this issue (Chow, C.-F., et al., 2017). Promotion of plastic substitutes and safe disposal of plastic waste requires urgent action plan to limit these kind of potential health hazards in future (Vandenberg, L. N., et al., 2017).

\section{II.MATERIAL \& METHODS}

Setting

The setting of the study was a community of Ali Raza Abad located on Raiwind Road Lahore Punjab Pakistan. Research design

The quasi-experimental study design was used in this study by using a pre and post-test phase.

Population

The target population of the study was 60 students of the high school of Ali Raza Abad, Raiwind road Lahore.

Sampling

Convenient sampling techniques were used in this study for data.

\section{Research instrument}

A well-structured and adopted questionnaire from the study of (Ceena, P. A, 2005) is used in order to collect the data from the participants.

Data gathering procedure

A formal written letter of permission to conduct the research. And the questionnaire was distributed to the primary school children.

\section{Analyze data}

Data analysis is done on SPSS (version 21). Data related to demographic variables were analysed in percentage and frequency form by using bar charts. Pre and post data related to knowledge on oral hygiene was analyzed by using paired T-test. A 95\% confidence level is used for the study and a $P \leq 0.05$ was considered statistically significant.

\section{Ethical consideration}

This research study met the national and international standards of research ethics as well as human subjects. The permission was taken from the research ethics committee of the Lahore school of nursing of the University of Lahore and also approved by the principal of high school institution in the community. All the students of high school showed full interest to join the interventional meeting after filling the consent form. All the data kept confidential.

\section{Study timeline}

Duration of the study was 4 month (September 2018 to December 2018).

\section{III.RESULTS}

This section represents the demographic characteristics of the participants and outcomes of the study regarding knowledge on plastic use and its health hazards. It also represents the results of paired t-test comparison before and after intervention and results for objective of this study "To assess the effects of health education session on knowledge of high school students regarding plastic use and its health hazards.

Section 1

Table\#1

\begin{tabular}{|c|c|c|c|c|}
\hline S\# & Demographic Characteristic & $\mathrm{N}$ & $\%$ & \\
\hline & & 60 & $100 \%$ & \\
\hline 1 & Class of Study & & & \\
\hline & $9^{\text {th }}$ Class & 35 & $47.3 \%$ & \\
\hline & $10^{\text {th }}$ Class & 25 & 33.8 & \\
\hline 2 & Education status of parents & & & \\
\hline & Illiterate & 12 & $16.2 \%$ & \\
\hline & Middle & 18 & $24.3 \%$ & \\
\hline & Matric & 30 & & $44.5 \%$ \\
\hline 3 & Age Group & & & \\
\hline & 12-13year & 4 & $5.4 \%$ & \\
\hline & 14-15year & 23 & $31.1 \%$ & \\
\hline & 16-17year & 33 & $44.6 \%$ & \\
\hline
\end{tabular}




\section{Table\#1}

\section{Interpretation:}

The above table\#1 describes Demographic data of respondents. According to this table total of 60 respondents participated in the study. It indicates that the majority of the participants were students from $9^{\text {th }}$ class $(47.3 \%)$ and $10^{\text {th }}$ class $(33.8 \%)$. The minimum age of respondents was 12 years and the maximum age 17 years. Most respondents were between the ages of 16 and 17 years $(44.6 \%)$.

\section{Section 2}

Table\#2

\begin{tabular}{|l|l|l|l|l|l|}
\hline & $\begin{array}{l}\text { Average Pre } \\
\text { mean }\end{array}$ & $\begin{array}{l}\text { Average Post } \\
\text { mean }\end{array}$ & $\begin{array}{l}\text { Average Pre } \\
\text { S.D }\end{array}$ & $\begin{array}{l}\text { Average Post } \\
\text { S.D }\end{array}$ & $\begin{array}{l}\text { Difference } \\
\text { between mean }\end{array}$ \\
\hline Knowledge & 8.98 & 16.85 & 39.04 & 73.26 & -7.867 \\
\hline
\end{tabular}

\section{Table\#2}

\section{Interpretation:}

Average pre and post interventional mean and standard deviation is mentioned above in table. Before intervention the knowledge score was 8.98 while post intervention knowledge was 16.85 . The average pre standard deviation of knowledge was 39.04 and post standard deviation was 73.26. The difference between pre and post score was 7.867 respectively.

\section{Comparison of pre and post test score of knowledge}

In this study paired t-test used for comparing the mean of knowledge in pre and post intervention phase similarly paired t-test always used for comparing the values of one sample in two different conditions.

Table\#3

\section{A. Paired Samples Statistics}

\begin{tabular}{|c|c|c|c|c|c|}
\hline & & Mean & $\mathrm{N}$ & Std. Deviation & $\begin{array}{l}\text { Std. Error } \\
\text { Mean }\end{array}$ \\
\hline & Pre_intervention(Knowledge) & 8.98 & 60 & 3.281 & .424 \\
\hline Pair 1 & Post_intervention(knowledge & 16.85 & 60 & 3.036 & .392 \\
\hline
\end{tabular}

\section{Table\#3}

\section{Interpretation:}

There is a significant difference between pre and post-test knowledge scores regarding knowledge on plastic use and health hazards. The mean of pre intervention session is 8.98 with sample size of 60 , standard deviation is 3.281 and standard error pf mean is .424 .

The mean of post intervention session is 16.85 with sample size of 60 , standard deviation is 3.036 and standard error pf mean is .392 .

There were 23 stem questions on knowledge on plastic use and its health hazards with 69 responses. Only 23 of these responses were correct. One mark was awarded for each correct response and no mark was awarded for wrong response and a total of 23 maximum attainable scores were used for knowledge regarding plastic use and its health hazards. A score of 0-7 marks out of 23 marks was graded be poor knowledge, a score of 8-14 marks out of 23 marks was graded as fair knowledge and a score of 15-23 marks out of 23 marks was graded as good knowledge.

According to our results the total mean of knowledge before intervention is 8.98 that fall in fair category but after intervention the total mean of knowledge is 16.85 that fall in good knowledge category. 
Paired Samples Correlations

\begin{tabular}{|ll|r|r|r|}
\hline & Sig. \\
\hline Pair 1 & $\begin{array}{l}\text { Pre_intervention(Knowledge) \& } \\
\text { Post_intervention(knowledge) }\end{array}$ & 60 & Correlation & Sig. \\
\hline
\end{tabular}

A. Paired Samples Test

\begin{tabular}{|l|r|r|l|l|l|l|l|}
\hline & \multicolumn{8}{|c|}{ Paired Differences } & t & df & Sig. \\
(2tailed)
\end{tabular}

\section{Interpretation:}

This table shows the exact results of pre and post-test in given table there are three main things that shows the significant increase in knowledge, first of all significant value of our results is less than .05 shows the null hypothesis is rejected " $\mathbf{H}_{\mathbf{0}}$ : There is no effect of health education session on knowledge of high school students regarding plastic use and its health hazards". So, alternative hypothesis is accepted and educational interventions regarding knowledge of plastic use and its health hazards were effective. In this table further a mean difference between pre and post reading that is -7.87 .

\section{IV.DISCUSSION}

This quasi experimental study finds out the positive impact of education session on 60 high school students in Lahore. Finding of this study indicated that there is a significant effect of health education session on the students to improve their knowledge regarding plastic use and its health hazards. Finding also show that most of the respondents were not aware about the ill effects and prevention of plastic use in pre-test results. After administering teaching session on plastic use and its health hazards the students acquired knowledge regarding the ill effects and prevention of use of plastic and drug abuse. The result show that the education session was effective and gain better score in post test result at $\mathrm{p}<0.05$.

The present study shows that health education on plastic use and its health hazards has a great impact on children's knowledge as is evidence through the post data result of the students in which the p-value indicated the positive effect which is $(0.00)$. The mean of pre knowledge of students is 8.98 and after educational interventions the mean of post knowledge is 16.85 . That is why the null hypothesis is rejected in favor of the alternative hypothesis. Another study finding shows a positive impact of health education in which the knowledge of the respondents increased after the educational intervention and the difference was found to be significant $(\mathrm{P}<0.001)$ shows that the mean percent of knowledge score of plastic hazards was $53 \%$ which increased significantly to $75 \%$ after health education intervention, $<0.05$ (Priya, A., et al., 2017).

A similar study conducted by (Manuel, J., et al., 2015) revealed that the pretest knowledge score was $42.52 \%$ and posttest knowledge score was $80.48 \%$ after administering effective teaching programme. The findings of this study shows that burning of plastic cause allergic asthma. The pre knowledge of students is $21.7 \%$ but after health education session the knowledge has improved to $53.3 \%$. In a similar study, it was found that the risk of asthma increases when the individuals are exposed to a plastic chemicals called phthalates etc (Athari, S. S, 2017).

The results of this study showed that, the students have good knowledge after health education session regarding ill effects of plastic use e.g. body hormone disruptions. Another study revealed that, plastic causes human and environmental pollution. It may cause hormone disruption and long term pollution (North, E. J., \& Halden, R. U, 2014).

The findings of this study revealed that the high school students have knowledge about plastic chemicals and food toxicology. The plastic chemical leaches out to the food when the temperature variations occur and they disrupts human health.

Another study showed leaching of chemicals from plastic bags transfer to humans as well as environment. Plastic bag packing for hot edible items causes migration of harmful chemicals to food items. These chemical include Styrene, Phthalates and Bisphenol A which causes diabetes and diseases of the heart and liver (Shimran, 
K., Kumar, R., \& Ram, R. K, 2017).

\section{Limitations}

The sample used for study belongs to one boy's high school. The shortage of time was the limitation of the study.

\section{Conclusion}

The plastic toxicity is a big issue on a large scale. The use of plastic can exert negative consequences on human health and environment as a results of exposure to the dangerous chemicals used in production of plastics. The ill effects of plastic can be reduce by educational intervention among students. The major findings of the study revealed that, majority of high school students had inadequate level of knowledge about plastic hazards by the mean value as 8.98 as presented in pretest. However, the result of post-test mean knowledge was significantly increased up to 16.85 that indicate the effectiveness of teaching program. In view of this, education for individuals (students) can be used as an effective source for improving knowledge and behavior even offering long-term benefits to the community.

\section{Acknowledgement}

This research work was not possible without the help and encouragement of many individuals to whom I am really very grateful. First and foremost, I would like to thank Mr. Muhammad Afzal (The Principal of Lahore School of Nursing) who allowed me for this study. Sir Muhammad Hussain and Ms Kousar Parveen, for being my preceptors and for being the greatest inspiration for my work when I had no idea to perform a research work, and who has been supportive and encouraging me throughout the whole process and freely offered their precious time to help me. Without their willingness to guide me in this study, this research work would not have come to completion. I am also grateful to my teacher Sir Muhammad Azhar, my friends and all those people who I contacted during this process. I also thank to the management of the university of lahore.

Last but not the least, I would like to thank my parents, my elder brother who provided endless moral, financial and motivational support for me during this research work.

\section{References}

A., Alvarenga, K. D. F., Cruz, P. C., Quadros, I. A. D., \& Jacob-Corteletti, L. C. B. (2016). Prevention in a school environment of hearing loss due to leisure noise. Audiology-Communication Research.

Babayemi, J. O., et al. (2016). "Overview of environmental hazards and health effects of pollution in developing countries: A case study of Nigeria." Environmental QualityManagement.

Bucheli, T. D., Strobel, B. W., \& Hansen, H. C. B. (2018). Personal Care Products Are Only One of Many Exposure Routes of Natural Toxic Substances to Humans and the Environment. Cosmetics.

Ceena, P. A. (2005). Effectiveness of a planned teaching programme to the high school students on hazards of plastic use in a selected school of mangalore (Doctoral dissertation).

Chow, C.-F., et al. (2017). Plastic Waste Problem and Education for Plastic Waste Management. Emerging Practices in Scholarship of Learning and Teaching in a Digital Era, Springer.

Chrompet, et.al. (2016). "The effectiveness of structured teaching programme regarding hazards of plastic use among school going children in Hilton matriculation higher secondary school."

D’Alessandro, N. (2014). 22 Facts about Plastic Pollution (And 10 Things we can do about it). Last Updated, 7.

Dobrzyńska, M. M., Gajowik, A., Jankowska-Steifer, E. A., Radzikowska, J., \& Tyrkiel, E.J. (2018). Reproductive and developmental F1 toxicity following exposure of pubescent F0 male mice to bisphenol An alone and in a combination with X-rays irradiation. Toxicology.

Dr. S. Ani Grace Kalaimathi, Dr. S. Vijayalakshmi, R. Jayalakshmi, (2016). Effectiveness of Structured Teaching Programme on Knowledge Regarding Hazards of Plastic Waste and its Safe Disposal.

Galloway, T. S. (2015). Micro-and nano-plastics and human health. In Marine anthropogenic litter (pp. 343-366). Springer, Cham.

Hammami, M. B. A., et al. (2017). "Survey on awareness and attitude of secondary school students regarding plastic pollution: implication for environmental education and public health in Sharjah city, UAE." Environmental Science and Pollution Research.

Helen, L., et.al. (2017). Plastics, Gender and the Environment Life cycle of plastics and its impacts on women and men from production to (marine) litter.

Joseph, N., Kumar, A., Majgi, S. M., Kumar, G. S., \& Prahalad, R. B. Y. (2016). Usage of plastic bags and health hazards: A study to assess awareness level and perception about legislation among a small population of Mangalore city. Journal of clinical and diagnostic research.

Kumar, P. (2018). "Role of plastics on human health." The Indian Journal of Pediatrics. Lineswala, M., Singh, S., \& Mishra, S. (2017). Mass education and awareness generation on plastic waste management.

Lopez Murcia Martin, J. (2015). "Social perceptions of single-use plastic consumption of the Balinese population." 
Manuel, J., et al. (2015). "An Educational Intervention Programme on Hazards of Plastic Waste and Its Disposal among Adults: A Rural Community Based Study." Nitte University Journal of Health Science.

Molstad, E. P., Heyer, K. P., Martin, K., \& Sardi, P. (2018). Reducing Single-Use Plastic in a Thai School Community: A Sociocultural Investigation in Bangkok, Thailand.

Murtaza Talpur, (2018). Plastic pollution in Pakistan.

Ni, H. G., Lu, S. Y., Mo, T., \& Zeng, H. (2016). Brominated flame retardant emissions from the open burning of five plastic wastes and implications for environmental exposure in China. Environmental Pollution.

Negussie, B. \& J. Mustefa (2017). "Community's perception of utilization and disposal of plastic bags in Eastern Ethopia." Pollution.

Priya, A., et al. (2017). "A study to assess the impact of education intervention on the knowledge regarding hazards of plastic food containers in school children." Internation Journal of Community Medicine And Public Health.

Proshad, R., et al. (2018). "Toixc effects of plastic on human health and environment: A consequences of health risk assessment in Bangladesh."

Rodgers, K. M., et al. (2014). Phthalates in food packaging, consumer products, and indoor environments. Toxicants in Food Packaging and Household Plastics, Springer.

Rustagi, N., et al. (2016). "Public health impact of plastics: An overview". Indian journal of occupational and environmental medicine.

Shiv, K. \& R. Dagar (2018). "Environmental Consciousness and Its Effect on Public Health." Environment Conservation Journal.

Su, S., Li, Y., Maschal, E., \& Ha, Y. (2015). Plastic Reduction Case Studies.

Talpade, J., et al. (2018). "Bisphenol A: An endocrine disruptor."

Vandenberg, L. N., et al. (2017). "Plastic bodies in a plastic world: multi-disciplinary approaches to study endocrine disrupting chemicals." Journal of Cleaner Production.

Zen, I.S., et al. (2014). "No plastic bag campaign day in Malaysia and the policy implication." Environment, development and sustainability. 